\title{
A Prática do Psicólogo em Saúde Coletiva: Um Estudo no Município de Fortaleza (CE), Brasil
}

The practice of the psychologist in public health: a study in the public net services of Fortaleza (CE), Brazil

La práctica del psicólogo en salud colectiva: un estudio en el municipio de Fortaleza (CE), Brasil

Liliane Brandão Carvalho Universidade de Fortaleza

Maria Lúcia M. Bosi Universidade Federal do Rio de Janeiro

José Célio Freire Universidade Federal do Ceará

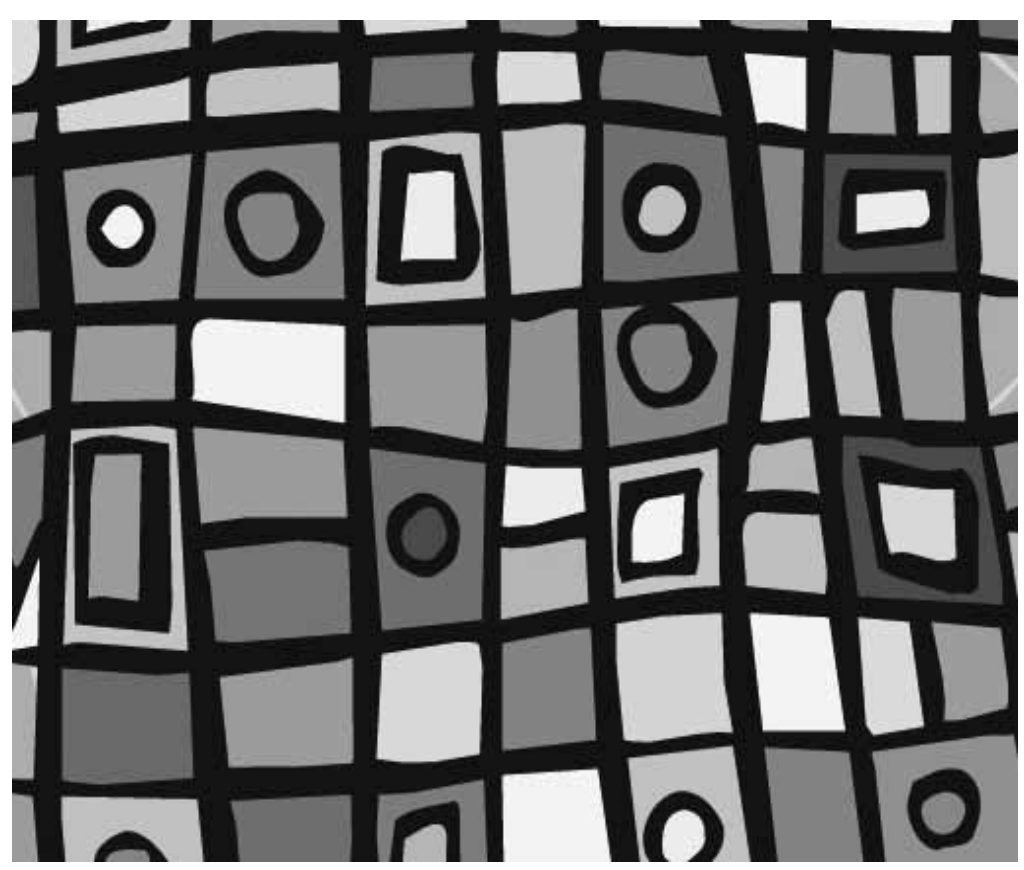


Resumo: O psicólogo na rede pública se depara com o desafio da inserção em instituições de saúde caracterizadas como locus específico de prática profissional. Busca-se compreender os sentidos atribuídos por um segmento de psicólogos à prática desenvolvida em serviços de saúde no Município de Fortaleza. Este estudo qualitativo, de enfoque crítico-interpretativo, foi composto por 8 das 22 psicólogas do quadro funcional da rede estadual de saúde. A técnica da entrevista individual em profundidade permitiu a construção de dois eixos da rede interpretativa referentes à inserção e aos saberes e fazeres em jogo. São muitas as dificuldades vivenciadas pelos psicólogos, sobretudo a formação acadêmica, percebida como insuficiente, e a influência do modelo biomédico como eixo organizador da assistência. Ante os usuários, o psicólogo desenvolve experiências mais técnicas e de ajustamento; há, contudo, atitudes que ultrapassam os modelos tradicionais de formação e de prática psicológicas.

Palavras-Chave: Psicólogo. Profissionais de saúde. Saúde pública. Sistemas de saúde.

Abstract: The psychologist in the public health sector deals with the challenge of fitting in non-psychiatric institutions characterized as one specific locus of professional practice of health. This study intends to understand the meanings attributed by the psychologists to their practice developed in the public health institutions in Fortaleza. Based on qualitative approach from a critical-interpretative perspective, the sample was composed by eight psychologists who are part of the public health team. The main technique employed was the non-directive individual interview that allowed to construct two different axis related to the objectives. The results point out many difficulties experienced by the informants that vary from a precarious academic graduation until the influence of the biomedical model in the assistance organization. In the services explored, the psychologist assumes attitudes of care as technique, adjustment, control and nullification of the difference. There are, however, experiences that go beyond the traditional models of education and practice.

Keywords: Psychologist. Health professions. Public health. Health systems.

Resumen: El psicólogo en la red pública se depara con el desafío de la inserción en instituciones de salud caracterizadas como locus específico de práctica profesional. Se procura comprender los sentidos atribuidos por un segmento de psicólogos a la práctica desarrollada en servicios de salud en el Municipio de Fortaleza. Este estudio cualitativo, de enfoque crítico-interpretativo, fue compuesto por 8 de las 22 psicólogas del cuadro funcional de la red estatal de salud. La técnica de la entrevista individual en profundidad permitió la construcción de dos ejes de la red interpretativa referentes a la inserción y a los saberes y haceres en juego. Son muchas las dificultades vividas por los psicólogos, sobretodo la formación académica, percibida cómo insuficiente, y la influencia del modelo biomédico como eje organizador de la asistencia. Ante los usuarios, el psicólogo desarrolla experiencias más técnicas y de ajustamiento; hay, sin embargo, actitudes que sobrepasan los modelos tradicionales de formación y de práctica psicológicas.

Palabras clave: Psicólogo. Profesionales de salud. Salud pública. Sistemas de salud.

Desafiado a inserir-se no campo da saúde coletiva, o psicólogo se depara com um contexto complexo, cuja dinâmica e historicidade se expressam no modelo assistencial vigente, marcado por questões de natureza política, âmbito no qual a própria definição de saúde vem sofrendo constantes alterações, em compasso com o movimento sociossanitário (Paim \& Almeida Filho, 1998; Mendes, 1999). Tal movimento, ao lado do delineamento de um novo sistema de saúde - o SUS - operou um deslocamento epistemológico no qual a saúde emerge como um fenômeno que deve ser tomado na interface com o contexto social e seus determinantes, nos planos objetivo e subjetivo.
A ampliação do conceito de saúde foi também reflexo de mobilização e de discussões das categorias profissionais da área, realizadas em várias conferências e encontros internacionais, nas quais também foram repensados as políticas de saúde e os modelos assistenciais vigentes, como ressaltam Mendes (1999) e Paim e Almeida Filho (1998).

A 8 a Conferência - um dos marcos do movimento sanitarista, no esteio de outros eventos que a sucederam (Mendes, 1999; Paim \& Almeida Filho, 1998; Ronzani \& Rodrigues, 2006) - legitimou os anseios sociais por mudanças e possibilitou a criação e a implantação de um sistema unificado de 
saúde, posteriormente denominado Sistema Único de Saúde (SUS) - processo social já concretizado em termos legais e legítimos, porém ainda em construção no cotidiano das práticas sociais. A saúde passa, então, a ser reconhecida como direito de todos e dever do Estado, cujas ações e serviços devem ser assegurados por esse sistema único. Ao lado disso, as discussões sobre integralidade na atenção à saúde e as mudanças na organização dos serviços e sistemas do setor proporcionaram a criação de novas áreas de atuação e a incorporação de outras especializações profissionais.

O Conselho Nacional de Saúde, através da Resolução no. 218/97 (Conselho Nacional de Saúde, 1997), reconhece como profissionais de saúde de nível superior mais de uma dezena de categorias profissionais, dentre elas, os psicólogos. Considerados oficialmente como profissionais de saúde, os psicólogos são convocados a contribuir com todo esse processo de revisão das políticas públicas em saúde e da organização dos serviços do setor.

Entretanto, no campo da saúde, notadamente nas instituições não-psiquiátricas caracterizadas como um locus específico de prática e de compreensão das questões relacionadas ao processo saúde-doença, ainda é significativa a presença da atenção biomédica, da verticalização da assistência e da técnica, em detrimento das relações intersubjetivas, principalmente entre profissionais de saúde e pacientes (Murphy \& Bennet, 2004). A ênfase da assistência são as tecnologias duras (Merhy, 2002; Merhy \& Franco, 2003), estruturadas nos instrumentos de produção de cuidados, em detrimento das chamadas tecnologias leves, de natureza relacional, que privilegiam o encontro, o agir singular entre os sujeitos trabalhadores e os usuários, nos planos individual e coletivo, implicados na produção do cuidado. Tal ênfase reduz o encontro entre os sujeitos nas instituições a uma obsessão pelo objeto de intervenção - o órgão doente ou a patologia - o que leva autores como Ayres (2004) a caracterizar essa assistência como uma "objetivação dessubjetivadora", na qual o doente deixa de ser visto como um todo e perde sua condição de sujeito para ser reduzido a uma parte ou ao órgão disfuncional.

Inegáveis são, reconhece-se, as conquistas alcançadas por esse modelo médico de atenção. Contudo, não se pode desviar da diminuta condição de sujeitos aqueles que procuram os serviços de saúde, grosso modo considerados como pacientes, ou seja, aqueles que aguardam, passivamente, uma intervenção que os contemple, embora, muitas vezes, esta se limite a reduzi-los a um rótulo diagnóstico ou a um simples número de prontuário.

A despeito do movimento social em saúde no contexto dos serviços públicos de saúde, já antes aludido, ainda há o predomínio político da corporação médica frente aos demais profissionais atuantes no setor. Ratifica-se, assim, uma divisão de trabalho que gera um sistema estratificado de ocupações em torno do médico: os denominados "profissionais paramédicos", caracterizados pela sociologia das profissões por não possuírem os elementos básicos para a conquista da autonomia técnica sobre suas atuações, tal como corpo de conhecimentos específicos, estratégias de controle do seu saber, responsabilidade e reconhecimento social (Bosi, 1996; Freidson, 1996).

Ao migrarem para certas áreas - como a saúde - os próprios psicólogos acabaram fazendo uso de saberes emprestados da prática clínica tradicional e privada em Psicologia, sem uma necessária revisão ou contextualização, como afirma Dimenstein (2001), dessa transposição de técnicas de uma realidade para outra. A organização do psicólogo no campo da saúde coletiva ficou comprometida, o que colaborou para perpetuar, nas instituições de saúde, a percepção dominante da profissão como uma prática que é sinônimo de psicoterapia, e reforçar, mais uma vez, a aproximação com as ocupações paramédicas. 
Não é, portanto, a alocação em uma instituição pública de saúde que definirá uma atuação como do âmbito da saúde coletiva, pois a prática do psicólogo na saúde deve ser pontuada por uma ampliação de suas ações para um modo coletivo (Dimenstein, 2001; Ronzani \& Rodrigues, 2006; Stam, 2000; Trindade \& Teixeira, 2000). Considera-se, então, essencial ao psicólogo uma contínua reflexão crítica sobre sua atuação para dar conta de "quem ele é", "do que faz" e "como faz", pois é na

tensão entre identidade e diferença, entre unidade e multiplicidade, que é possível situar nossa subjetividade, nossa existência, o campo da Psicologia e a atuação do psicólogo. ...é melhor afirmar uma identidade em crise do que sermos (nós psicólogos) esses "técnicos" com contribuições convencionais, entediantes, repro-duzindo técnicas e procedimentos sem nenhuma postura crítica. (Coelho Junior, 1996, pp. 310-312, grifo dos autores)

E, ao se falar em reflexão, em assumir postura crítica, vai-se ao encontro da ética, entendida para além das normas de conduta prescritas no Código de Ética da profissão, mas mais condizente com a exigência de uma reflexão crítica e de uma avaliação pelo psicólogo do sentido e dos fins de sua ação.

Eis porque, para Lévinas, o primeiro gesto é ético. Dito de outro modo, a ética é a questão original, é a filosofia primeira: "A deposição da soberania pelo 'eu' é a relação social com outrem, a relação des-inter-essada. Escrevo-a em três palavras para realçar a saída do ser que ela significa" (Lévinas, 1982, p. 43, grifo dos autores).

Acredita-se ser preciso, então, pôr em questão o saber e o poder sobre o outro, sobre as coisas já possuídas e as relações cristalizadas, porque o respeito ao outro em sua diferença permite vê-lo, como, por exemplo, o doente na instituição de saúde, não simplesmente como aquele que precisa de um "conserto" ou de um paliativo, mas, sobretudo, como aquele de quem o profissional de saúde se aproxima em seu sofrer. O cuidado não implica a rejeição do uso da técnica ou do controle da doença. Abordar, porém, a questão do cuidado é ir além e redimensionar a prática nas instituições de saúde a partir de uma atitude de resposta à necessidade do outro que se paute pelo respeito, pela escuta de seu sofrimento e pelo acolhimento de sua singularidade.

Na realidade, a área da saúde necessita que o cuidado seja caracterizado como a tarefa orientadora de todos os profissionais, pois a arte da assistência à saúde não pode reduzir-se à mera manipulação de objetos. A enfermagem, por exemplo, embora seja reconhecida como a profissão da saúde que há tempos discute e problematiza a questão do cuidado no seu modo de intervenção, ainda revela em sua práxis a preponderância de um cuidado hierarquizado, voltado mais para a habilidade técnica e para as regras institucionais, conforme uma pesquisa sobre o significado do cuidar entre enfermeiras (Waldow, 2004).

É preciso articular a intervenção técnica com outros fatores não tecnológicos, como o envolvimento, o afeto, o compartilhamento e a responsabilidade, pois "nunca, quando assistimos à saúde de outras pessoas, mesmo estando na condição de profissionais, nossa presença na frente do outro se resume ao papel de simples aplicador de conhecimentos" (Ayres, 2004, p. 84). A implicação dessa questão é, no caso específico explorado nesta pesquisa, o psicólogo colocar seu papel de perito em xeque (Freire, 2003) e ousar romper os modelos tradicionais de assistência limitados a posturas instrumentais de tratamento, controle e cura, buscando pautar sua prática por outro modo de atenção, que dê conta do acolhimento e do cuidado para com o usuário.

O cuidado surge como uma crítica, apontam Pinheiro e Guizardi (2005), capaz de romper o discurso hegemônico da racionalidade médica e de corresponder à demanda 
por uma integralização da assistência, integralidade essa que se coloca como um dispositivo político com implicações no espaço da intersubjetividade, o que quer dizer que, como uma prática social, busca reconhecer as diferentes visões de mundo, saberes e diálogos próprios do campo da saúde.

Em Ayres (2005), o cuidado é reconhecido como um verdadeiro desafio à organização dos serviços públicos de saúde do País. Há urgência de uma nova atitude de cuidado para com o outro, que se abra ao encontro intersubjetivo, ao diálogo e à afecção pelo outro. Dessa forma, considera-se premente discutir a compreensão dos psicólogos em relação à sua prática em seu cotidiano, e, de modo mais específico, à discussão aqui empreendida, tomando como contexto a rede pública de saúde.

Este estudo objetivou compreender os sentidos atribuídos à pratica do psicólogo a partir das percepções de um segmento específico de psicólogos - aqueles cujas práticas se inserem no cotidiano de instituições públicas - tomando como espaço de estudo a Rede Estadual de Saúde da cidade de Fortaleza (CE), notadamente de sete das suas instituições hospitalares e de um centro de saúde.

\section{Aspectos metodológicos}

Este estudo, conforme já aludido, foi desenvolvido junto a psicólogos que atuavam em instituições públicas da Rede Estadual de Saúde do Ceará. Essa esfera pública constituiu o espaço para desenvolver a pesquisa, tendo em vista a configuração de uma realidade singular de prática e de compreensão do processo saúde-doença. Cabe assinalar que o interesse foi sempre o de investigar a realidade desses profissionais na rede pública, desde que fossem do quadro funcional permanente do nível estadual. Contudo, o campo revelou, à época da realização da pesquisa, psicólogos efetivos na Secretaria de Saúde lotados em instituições hospitalares - em sua maioria, hospitais gerais - numa instituição psiquiátrica e em um centro de saúde apenas. Daí o privilégio do âmbito da atenção terciária, onde estavam alocados na configuração funcional da Secretaria de Saúde do Ceará - nível esse, vale ressaltar, incluído no âmbito do movimento sanitarista e da saúde coletiva, a partir do princípio da integralidade que preconiza a integração dos três níveis de atenção.

O foco deste estudo, portanto, é buscar os sentidos do fenômeno investigado, com base no método fenomenológico e na perspectiva crítico-interpretativa da hermenêutica filosófica de Gadamer (1997). A partir dessa organização, passou-se à narrativa acerca dos sentidos desvelados nas falas das informantes, com base nessa hermenêutica, para possibilitar novas leituras e maior aprofundamento da questão do cuidado na prática dos psicólogos na rede estadual de saúde, pois, em Gadamer (1997), o foco sai da explicação e da verificação para a compreensão do fenômeno investigado.

Compreender, nessa perspectiva, implica a produção de um sentido diferente e, portanto, original, pois o verdadeiro sentido de um texto não se exaure no dito pelo psicólogo nem em um determinado ponto que supostamente esgotaria a compreensão; ao contrário, implica um processo infinito, uma vez que "constantemente, surgem novas fontes de compreensão que tornam patentes relações de sentido insuspeitadas" (Gadamer, 1997, p. 446). Este estudo qualitativo é, portanto, interpretativo, do ponto de vista crítico, a partir da hermenêutica gadameriana, porque ambiciona compreender os sentidos da vivência dos psicólogos no contexto público da saúde, ou seja, repondo a subjetividade na materialidade a que se vincula, e é também de caráter exploratório, porque não foram encontrados na literatura estudos significativos, nem embasamentos teóricos, da questão do fenômeno em investigação. 
De acordo com Amatuzzi (1996), tal modalidade de pesquisa insere-se na tradição qualitativa, cujo objeto é de natureza subjetiva - o vivido ou a experiência imediata préreflexiva - e cuja intenção é o privilégio do intencional e a descrição do seu significado, levando em consideração a subjetividade do pesquisador, o que impõe reflexividade (Bosi \& Mercado, 2004).

A pesquisa qualitativa também se caracteriza por vincular a subjetividade dos entrevistados, enquanto sujeitos históricos e sociais, à subjetividade do pesquisador, desconstruindo, assim, a crença na neutralidade da ciência, sendo considerada como uma construção que ocorre sempre em relação, sempre no encontro intersubjetivo - entre o pesquisador e os informantes da pesquisa (Bosi \& Mercado, 2004). Nesse modelo, portanto, o pesquisador é também sujeito epistêmico da mesma forma que o "objeto" é também sujeito e mostra-se reticente ou recusa-se, afirma Minayo (2000), a ser revelado apenas através de números.

A busca foi por uma aproximação qualitativa da realidade investigada, sem a intenção de generalizar conceitos ou esgotar o tema. A inquietação era saber como os psicólogos desenvolviam suas práticas no serviço de saúde, se eles reproduziam a prática instrumentalizada da biomedicina, se eles refletiam sobre suas atuações, se buscavam outros modos possíveis de atuação e se eles poderiam ter, no cuidado para com o outro, um eixo de suas ações na área.

De acordo com informações obtidas junto à Secretaria Estadual de Saúde (SESA), foram listadas oito instituições de saúde localizadas na capital cearense que tinham psicólogos em seu quadro funcional no momento de realização deste estudo.

Sabendo que, no estudo qualitativo, o interesse não é na quantidade de sujeitos, mas na qualidade das informações ante o objeto a ser desvelado, foi estabelecido diálogo com um psicólogo em cada uma dessas instituições, que se tornou o informante-chave, o que significa dizer que ele possuía o potencial (acúmulo subjetivo) de desvelamento do fenômeno investigado. Os critérios de seleção dos oito informantes foram os seguintes: ser do quadro efetivo de funcionários da instituição, ter maior tempo de serviço (naquelas onde havia mais de um psicólogo), não ser um profissional lotado na área de recursos humanos e não estar no setor da saúde como desvio de função - uma prática comum no contexto investigado, onde os funcionários graduados em Psicologia e lotados no nível técnico-administrativo foram desviados ou solicitaram transferência para as unidades de saúde.

Para a apreensão e a construção das informações, foram realizadas entrevistas nãodiretivas, cujos conteúdos foram gravados, após anuência dos informantes, e transcritos. Como uma investigação fenomenológica começa sem nada pressupor a não ser o retorno aos fatos tal como eles se dão na realidade, a intenção foi facilitar a livre exposição das experiências vivenciadas pelas psicólogas participantes. Quanto ao local de realização das entrevistas, a maioria aconteceu nas salas dos serviços de Psicologia das próprias instituições; apenas uma ocorreu no consultório particular da entrevistada, após o seu horário de trabalho institucional e por solicitação da mesma.

\section{Resultados}

Com os depoimentos transcritos, passou-se para a fase de organização e interpretação das informações. Primeiro, foram realizadas leituras exaustivas e repetidas, visando à impregnação dos conteúdos das entrevistas. Deu-se então a categorização das temáticas singulares, que permitiu passar para a classificação das informações em temas, 
dimensões e subdimensões, que, por sua vez, possibilitaram, de modo inter-relacionado e a partir de uma postura crítico-interpretativa, a construção da rede interpretativa que evidenciou dois temas centrais: 1) a inserção no campo da saúde coletiva e 2) a prática do psicólogo - saberes e fazeres em jogo. Cada tema, por sua vez, foi desdobrado em distintas dimensões, a saber:

Tabela 1. Rede de significados.

\begin{tabular}{llll}
\hline Temas & Dimensões & & \\
\hline Inserção & Chegada & Dificuldades e desafios & Condições de trabalho \\
Prática & Várias facetas do & modelo biomédico & usuário como o outro \\
& modelo dominante & & \\
\hline
\end{tabular}

Com base nesse percurso, passou-se ao texto interpretativo, tendo, de um lado, o caminho teórico construído acerca da questão da saúde e do cuidado, de outro, as narrativas das psicólogas informantes que versaram sobre suas experiências cotidianas no serviço público e as percepções atribuídas ao cuidado, e, por fim, os próprios pressupostos dos pesquisadores, em uma teia de significações.

\section{A inserção no campo da saúde coletiva}

O primeiro tema da rede interpretativa possibilita compreender o contexto em que se dá a inserção dos participantes, a partir do desdobramento em dimensões intrínsecas às vivências dessas psicólogas na rede estadual de saúde. Referentes a esse tema, encontram-se distintas dimensões nomeadas, como segue: a chegada, as dificuldades e os desafios e, por último, as condições de trabalho.

Quanto à dimensão relativa à chegada à rede pública, com exceção de uma psicóloga - efetivada por meio de concurso público -, todas as demais entrevistadas entraram na instituição de saúde através de contratos com o Estado, mais especificamente, e, em sua maioria, através de transferências de outras áreas da rede estadual, como a educação e a segurança pública.

Quanto às profissionais procedentes da educação especial, evidenciou-se a intervenção do Estado e seu papel regulador da prática profissional das distintas corporações, dentre elas a do psicólogo. No contexto examinado, verificou-se que, através de um decreto governamental, a categoria teve sua expansão comprometida, dada a impossibilidade de contratação de novos psicólogos para a rede estadual. Posteriormente, esse papel estatal se fez presente, quando houve o reconhecimento oficial da Psicologia como uma profissão de saúde e a transferência obrigatória de todos os psicólogos lotados na educação para a área da saúde. Dessa forma, o status e a reserva de mercado de trabalho foram administrados pelo poder estatal, conforme assinalado por Freidson (1996), um dos importantes autores do referencial sociológico sobre as profissões. Tal ato se evidencia em depoimentos como o que se segue:

Nesse reconhecimento, entramos todos nós psicólogos, fisioterapeutas, fono, TO. E então a gente teve que ser transferido da educação. Agora a gente estava reconhecidamente profissionais de saúde... a prioridade era lotar os profissionais nos hospitais de referência do Estado, que não existia, assim, quase nenhum tinha psicólogo no Estado... A gente não podia ficar nas escolas... (Informante 4) 
"Lembro que na época me senti assim como tirando a terra dos meus pés. Tinha, o quê? Já uns quinze, dezesseis anos de Estado, e você refazer tudo" (Informante 4).
Já mais recentemente, no ano 2000, outra intervenção governamental ressoou diretamente nessa chegada à rede pública, quando houve a reestruturação do Instituto de Previdência do Ceará (IPEC) e mais psicólogas que atuavam junto a portadores de necessidades especiais foram transferidas para hospitais.

É consenso na literatura a falha nos modelos curriculares dos cursos de graduação em Psicologia quanto ao diálogo com a saúde como uma dimensão coletiva e com as políticas públicas (Chiattone, 2002; Dimenstein, 2001; Hepworth, 2004; Lo Bianco, Bastos, Nunes, \& Silva, 2001; Spink, 2003; Stam, 2000; Ronzani \& Rodrigues, 2006), embora iniciativas de reestruturações curriculares observadas em anos recentes possam ser consideradas estratégias de reversão desse quadro, devendo constituir objeto de investigações a serem desenvolvidas nesse campo. A prática nas instituições de saúde demanda, porém, não se restringir à ênfase individualista das teorias psicológicas clássicas e ir além, para tentar dar conta da trama social implicada nas ações e nos serviços que envolvem tanto o usuário como a família e os profissionais de saúde. A dificuldade de inserção do psicólogo, treinado no meio acadêmico essencialmente para a prática clínica, fica evidente neste depoimento: " $A$ gente vem com uma visão de clínica, e quando você chega na instituição hospitalar, você toma um choque. ...E aí na rede pública, o tipo de atendimento que a gente faz, tudo isso vem por água abaixo" (Informante 1).

As novas diretrizes curriculares para os cursos de graduação de todo o País, já aprovadas pelo Conselho Nacional de Educação no ano 2004, buscam suprir essa demanda e fundamentar a formação e a prática profissionais a partir do compromisso e da compreensão crítica dos fenômenos socioculturais. O próprio Código de Ética Profissional do Psicólogo (CFP, 2005), que buscou contemplar a diversidade do exercício profissional, tem ao longo de todo o seu texto um compromisso maior com a realidade social compreendida como um dos eixos que atravessam todas as práticas dos psicólogos.

Ainda na dimensão dificuldades e desafios, outro significado remete ao fato de muitas psicólogas, oriundas da área da educação, ao se depararem com o novo na área da saúde, vivenciarem a inserção como um choque: "Lembro que na época me senti assim como tirando a terra dos meus pés. Tinha, o quê? Já uns quinze, dezesseis anos de Estado, e você refazer tudo" (Informante 4).

Desalojadas da educação e em choque na saúde, de qualquer modo, as psicólogas lidam com o outro - seja o paciente ou o portador de necessidades especiais. No entanto, parece ocorrer algo sui generis: é como se a prática anterior dessas profissionais não implicasse também a promoção da saúde, lidar com o sofrimento do outro, em uma relação de respeito e acolhimento desse sujeito. É preciso, realmente, no momento do encontro com o outro no serviço de saúde, um repensar da própria prática para que o psicólogo "se despoje do lugar do especialista, portador de um saber a ser transmitido e passe a funcionar como um mediador, um entre" (Andrade \& Morato, 2004, p. 347). Promover a saúde do outro se configura em um sentido próprio à prática do psicólogo, que transversaliza todos os seus campos profissionais, a despeito das especificidades próprias de cada um. Especialista aqui entendido como o profissional ocupado, sobretudo, em reproduzir sua técnica ou o seu saber sobre o outro sem necessária reflexão crítica ou respeito à alteridade, conforme problematiza a ética da alteridade radical (Lévinas, 1988).

Uma informante relata sua incessante busca por estudos novos e por especialização, expondo como motivo sentir-se intimada a responder ao outro, o seu usuário:

A clientela chegava e começava a me trazer assuntos diversos e solicitações diversas 
de coisas que eu não dominava... não podia negar a origem de ninguém, nem religiosa, nada. Tinha que compreender aquilo para compreender o caminho onde as pessoas pisavam... Então começo a ter visões diferentes, condutas diferentes. (Informante 6)

Além da exigência de reflexão, outro desafio colocado para as informantes é, portanto, a necessidade de capacitação. Entre as especialistas na área de família, de adolescência, de saúde mental e saúde pública, algumas com mestrado em saúde pública, constatou-se maior sensibilidade, questionamento e busca por constante aprendizagem, o que lhes possibilitou assumir - ou no mínimo, caminhar na direção de uma outra atitude para com os usuários dos serviços.

Finalmente, outra dimensão que surgiu de forma recorrente nas narrativas de todas as psicólogas entrevistadas foi a realidade do serviço público, mais especificamente, as condições e as peculiaridades de trabalho na Rede Estadual de Saúde. Nessa dimensão, denominada condições de trabalho, um significado de repercussão direta na vivência dessas profissionais é a sobrecarga de trabalho, dadas a carência de pessoal, a precariedade e a demanda significativa pelos serviços, que geram sentimentos de insatisfação e tensão entre os membros da equipe: "Ficou uma coisa assim ruim no relacionamento da equipe, e a gente não estava conseguindo dar conta do nosso usuário. Acabava que ele ficava relegado, porque a gente não tinha tempo" (Informante 1).

São muitas as repercussões das condições de trabalho na prática do psicólogo, o que leva a discutir os fazeres e os saberes em jogo nas instituições públicas, práticas e conhecimentos que só podem ser considerados a partir dessa entrada peculiar na área, da precária formação acadêmica e da diversidade de desafios impostos ao psicólogo.

\section{Prática do psicólogo: saberes e fazeres em jogo}

Na primeira dimensão deste segundo tema, as várias facetas do modelo dominante em Psicologia, os aspectos que se sobressaem relacionam-se à migração dessas profissionais para a complexidade do serviço público. Um primeiro elemento que emerge desse modelo dominante é a intervenção tecnicista, seja por meio da prática individual ou em grupo, com foco no tratamento. A profissional, numa postura passiva, estabelece sua rotina de trabalho e seu modo de atuar frente ao outro, e limita-se a aguardar em sua sala a solicitação de atendimento:

\begin{abstract}
Se eles sentem necessidade eles (os pacientes) me chamam, porque é a postura realmente do psicólogo: manter uma certa distância e eles procurarem... Estou aberta, desde que me solicite... só vou quando sou solicitada ou pelo médico ou outro da equipe, o próprio paciente ou alguém da família... (Informante 5)
\end{abstract}

A realidade dos serviços de saúde impõe uma ruptura com os muros do seu consultório não raro, trasladado para a instituição, daí o porquê de se considerar essa reflexão sobre a práxis como uma exigência ética. O psicólogo inserido na saúde coletiva, que ainda se limita à relação tecnicista e passiva, revela pouca reflexão sobre sua atuação e sobre o seu papel de perito, permanecendo em uma postura de alergia à diferença (Lévinas, 1988).

Agindo de uma forma alérgica à alteridade, esses psicólogos demonstram sentirem-se donos de um saber sobre o outro, o que parece lhes outorgar o direito de saber mais do que ele mesmo não se sabe, como já afirmou Freire (2003). Acreditam saber o que é o melhor para aquele usuário e acabam por anular suas necessidades e singularidades: " $E$ na fase do começo da recuperação deles que eles precisam de respostas rápidas, precisam de uma coisa mais direcionada, uma coisa 
mais comportamental, mesmo, de mudança de hábito, de mudança de comportamento" (Informante 7).

\begin{abstract}
Atuar em equipe é outro desafio no trabalho, não apenas em instituições de saúde no território investigado, mas também em outros contextos institucionais, conforme aponta a pesquisa de Lo Bianco et al. (2001). Uma informante, inclusive, revela a ausência de diálogos com uma colega de profissão, com quem divide apenas fisicamente $-\mathrm{o}$ setor de Psicologia da instituição:
\end{abstract}

A gente não tem um setor de Psicologia. Só somos duas, e se trabalha praticamente isolado, porque faço as minhas coisas e ela as dela... A gente raramente se comunica. Isso é muito difícil, acho que para a Psicologia não é bom. Me sinto só, como psicóloga. (Informante 5)

Seria ingenuidade atribuir a prática isolada da Psicologia apenas ao predomínio do saber tradicional da área clínica, sem levar em conta a organização técnica do trabalho, pois a instituição de saúde se encontra estruturada pela assistência vertical e hierarquizada. Profissionais paramédicos inserem-se como meros coadjuvantes da assistência e, desse modo, a tarefa do psicólogo não é percebida como essencial: "Então, fica muito uma ilha nessa história toda. ...Muito isolada, quer dizer, interdisciplinaridade não existe. Assim, uma coisa esporádica" (Informante 3).

sua ałuação na saúde, no cristalizar-se em um modelo de atenção

assistencialista, diretamente associada com a relação individualizada (Ayres, 2001)
Quando ela (a paciente) vem, com o prontuário dela, que eu já vejo o que ele (o médico) escreveu, então digo a ela o que é melhor para ela e faço o meu atendimento, entendeu? Mostrando as coisas da vida, dizendo, mostrando a importância de outras coisas na vida além da mama, que ficar com a mama doente não compensa, e tal. (Informante 2)

Outro aspecto a ser ressaltado nessa postura é sua aproximação com a anulação da alteridade, com a relação "interessada" no outro como objeto, o que configura uma verdadeira oposição à relação des-inter-essada exigida pela ética da alteridade, consoante o filósofo Lévinas. A inquietação existe, sobretudo, na diminuta ocorrência de diálogos com outros saberes, na falta de clareza para o próprio psicólogo do sentido de sua atuação na saúde, no cristalizar-se em um modelo de atenção assistencialista, diretamente associada com a relação individualizada (Ayres, 2001) e individualizante.

Em consonância com a orientação dialética adotada neste estudo, que propõe a demarcação não apenas do que se mostra recorrente, mas, sobretudo, das contradições, há que assinalar a presença de experiências cotidianas na rede estadual que contradizem o modus operandi dominante, aproximandose de dimensões psicossociais de atenção e de promoção da saúde - às quais as psicólogas deste estudo não permanecem restritas, buscando concretizar suas atuações em interface com outros saberes, em prol de responder ao apelo vindo do outro, reconhecido e respeitado como um sujeito. Essas experiências corroboram, portanto, a mudança mais significativa apontada por Lo Bianco et al. (2001): a tendência "psicologizante" isolada está perdendo espaço em novos mosaicos de inserção dos psicólogos: "Tenho uma visão hoje estando no serviço que não dá para você ficar só num ponto. A gente realmente para ajudar a pessoa - que é uma coisa que eu faço - (tenho que) trabalhar as outras questões que essa pessoa traz..." (Informante 1). 
As especificidades da instituição de saúde, que envolvem o limite de tempo, a elevada demanda por atendimentos, a escassez de pessoal, a possibilidade de o usuário não retornar-devido, por exemplo, a dificuldades socioeconômicas -, a burocracia do serviço público e a própria situação emergencial de doença e/ou hospitalizações, exigem uma atuação mais ativa do psicólogo, no sentido de romper os limites de sua sala e se fazer presente nos múltiplos espaços institucionais, construindo diálogos coletivos com os outros saberes atuantes no campo da saúde.

Os demais tipos de relação psicológica podem ser agrupados em aconselhamento ou orientação, um grupo de prática comum entre as informantes: "A Psicologia entra nessa hora, em intervenções indiretas, com questões que nem sempre são só psicológicas, questões da vida prática, diária, a gente entra para orientar a família" (Informante 8).

Outra dimensão que emerge das falas das psicólogas refere-se à crítica ao modelo biomédico pela sua tradicional negligência à condição subjetiva, perspectiva acentuadamente presente na rede estadual de saúde no espaço investigado, no qual não há o reconhecimento do usuário como um sujeito, dotado de história, de expectativas e desejos: "Não vê-la só como a pessoa que tem HIV - muitas vezes isso acontece: a pessoa tem HIV e se foca só na patologia. Não!" (Informante 1).

Esse modo de pensar e fazer saúde, preconizado pelo referido modelo, base da formação de profissionais que atuam no campo da saúde - mais ocupado com a doença, menos com a pessoa enferma, e mais voltado para o tratamento e a intervenção tecnicista - tem, então, preterido o encontro intersubjetivo entre usuário e profissional de saúde e considerado o primeiro não um interlocutor, e sim, um receptor passivo das orientações medicamentosas:

\begin{abstract}
O momento assistencial pode (e deve) fugir de uma objetivação "dessubjetivadora", quer dizer, de uma interação tão obcecada pelo "objeto de intervenção" que deixe de perceber e aproveitar as trocas mais amplas que ali se realizam. Com efeito, a interação terapêutica apóia-se na tecnologia, mas não se limita a ela. (Ayres, 2004, p. 85)
\end{abstract}

O psicólogo do serviço estadual de saúde aqui investigado ainda vivencia, no entanto, a hegemonia desse modelo assistencial de forma muitas vezes submissa, em que o profissional médico delega ao psicólogo determinadas tarefas, depois de fazer - ele mesmo - a identificação da necessidade de intervenção do psicólogo e do encaminhamento que considera adequado. Assim, o psicólogo inscreve a sua prática como a de um profissional paramédico termo já explicitado. Tal questão implica a correspondência com uma das estratégias fundamentais desenvolvidas pelos médicos junto aos demais profissionais atuantes na área da saúde: o controle do conhecimento científico sobre a doença e sobre a saúde nesse campo de saber e prática (Bosi, 1996).

O predomínio de uma voz apenas envolve ainda uma tensão entre os profissionais médicos e os paramédicos, explicitada no seguinte depoimento:

\footnotetext{
Dizem assim: converse lá com a psicóloga, ela é que é para lhe ouvir. ...Ela tem tempo - é essa a história! E fica assim. Essa história que ela tem tempo: atendo cinco fichas por dia, geralmente marco dois ou três retornos, e os médicos atendem 16 pessoas no mesmo período de tempo, ou menor.. (Informante 3)
}

Para além de reafirmar a especificidade da sua prática técnica, o psicólogo precisa também se comprometer com o "desenvolvimento de atitudes e espaços de genuíno encontro intersubjetivo" (Ayres, 2004, p. 86) na própria 
equipe de trabalho, para que possam ocorrer rupturas nessas atuações individualizadas e estanques.

Passamos agora à terceira dimensão explorada neste tema, o usuário como o outro, que foi revelada nos depoimentos das profissionais que se posicionaram com alguma abertura para a alteridade e com uma postura mais sensível frente àquele que busca ser acolhido em sua dor e respeitado em sua singularidade, distante, portanto, daquelas relações de anulação da diferença, típica da ênfase objetivadora e tecnicista dos modelos tradicionais - seja o da Psicologia ou o da biomedicina. Assim, o trecho seguinte melhor sintetiza a necessidade sentida pela própria psicóloga de, no seu cotidiano na instituição de saúde, ter uma outra atitude para com o outro:

\begin{abstract}
As pessoas que recebem um diagnóstico positivo para HIV sofrem muito (maior ênfase). Sofrem no momento do diagnóstico, sofrem no processo delas vivendo com o HIV... Então, é uma patologia cercada de histórias de sofrimento, de perdas afetivas. Então, você imagina: o que é receber um diagnóstico positivo para HIV e não poder falar... (Informante 1)
\end{abstract}

\section{Considerações finais}

No âmbito deste estudo, foi constatado que o psicólogo assume o desafio de inserção no campo da saúde coletiva a partir, sobretudo, da transferência de outra área de atuação, notadamente da educação, sofrendo, assim, as injunções do poder estatal no controle sobre seu processo de profissionalização, sobre o status e sobre a reserva de mercado de trabalho.

As lacunas presentes na sua formação acadêmica, ao que parece, constituem de início um importante obstáculo à sua atuação na área, haja vista o privilégio do modelo tradicional da Psicologia e seu afastamento do contexto social dos serviços públicos, ou seja, do diálogo com a saúde em sua dimensão coletiva.

O modelo biomédico - outra dificuldade vivenciada - ainda é muito presente no contexto investigado. Não cabe, seguramente, negar os seus alcances, mas também não cabe, ao psicólogo, persistir no privilégio da técnica - preconizado por esse modelo - em detrimento do diálogo intersubjetivo ou do encontro com o outro.

O campo da saúde coletiva demanda um modo diferenciado de estar a serviço do outro. Em relação ao psicólogo, a demanda é por uma postura crítico-reflexiva mais comprometida com o contexto sociocultural e político de sua prática e com o compartilhar de ações e responsabilidades que ultrapassem rótulos diagnósticos. É-lhe exigido, ainda, que vá ao encontro do usuário, fazendo-se presença constante nos múltiplos espaços institucionais - rompendo, dessa forma, com a prática tradicional do perito e de anulação da alteridade.

Na investigação realizada, foram identificadas duas significativas modalidades de prática: a primeira, de maior predominância, caracterizada mais pela ocupação e interesse no outro como objeto de intervenção técnica. Como um profissional paramédico, esse psicólogo pauta sua prática tanto pela hierarquia verticalizada da assistência e pelo saber médico quanto pela ausência de uma reflexão crítica, não conseguindo ir além de uma postura tecnicista.

O segundo conjunto de experiências, contudo, já revela uma superação da relação sujeitoobjeto. A atenção é para com o sujeito, com quem é estabelecida uma relação dialógica, intersubjetiva, na qual o usuário não é mais um simples receptor passivo, e sim, um outro interlocutor. A atitude dessas psicólogas revela uma abertura necessária ao encontro com o outro, implicando a compreensão do cuidado como uma atitude ética, em oposição à atitude de cuidado como técnica. 
Uma vez mais, deve-se ressaltar, o cuidado como escuta ética não implica rejeição da técnica ou da necessária intervenção sobre a doença - o que há é a exigência de superação dialética, e não de negação. Em suma, o que se reitera é a necessidade de o psicólogo se assumir como um sujeito éticopolítico que busca constantemente refletir sobre seu modo de estar a serviço do outro, sobre as relações construídas em seu entorno e sobre a criação de espaços de diálogo e de revisão das práticas de saúde, em especial aquelas mantidas e reproduzidas no espaço público.

Embora tenha se revelado ainda incipiente, foi gratificante presenciar indícios dessa postura no cotidiano de psicólogas da rede estadual investigada, as quais têm buscado assumir o papel-chave de autoras e atrizes da difícil tarefa de tecer a intricada teia de revisão das práticas de Psicologia e de saúde coletiva.

Liliane Brandão Carvalho*

Psicóloga, Mestre em Psicologia pela Universidade Federal do Ceará; professora da Universidade de Fortaleza.

Maria Lúcia M. Bosi

Psicóloga, Doutora em Saúde Pública; pesquisadora-visitante do Departamento de Saúde Comunitária/ Universidade Federal do Ceará; professora adjunta da Universidade Federal do Rio de Janeiro.

\section{José Célio Freire}

Psicólogo, Doutor em Psicologia; professor adjunto do Departamento de Psicologia/Universidade Federal do Ceará.

*Endereço para envio de correspondência:

Rua Joaquim Nabuco, 275/801 - Meireles. Cep: 60125-120 - Fortaleza - CE

Email: lilianebcarvalho@gmail.com 


\section{Referências}

Amatuzzi, M. M. (1996). Apontamentos acerca da pesquisa fenomenológica. Estudos de Psicologia (Campinas), 13(1), 5-10.

Andrade, A. N., Morato, H. T. P. (2004). Para uma dimensão ética da prática psicológica em instituições. Estudos de Psicologia (Natal), 9(2), 345-353.

Ayres, J. R. C. M. (2001). Sujeito, intersubjetividade e práticas de saúde. Ciência \& Saúde Coletiva, 6(1), 63-72.

Ayres, J. R. C. M. (2004). Cuidado e reconstrução das práticas de saúde. Interface, 8(14), 73-92.

Ayres, J. R. C. M. (2005). Hermenêutica e humanização das práticas de saúde. Ciência \& Saúde Coletiva, 10(3), 549-560.

Bosi, M. L. M. (1996). Profissionalização e conhecimento: a nutrição em questão. São Paulo: Hucitec.

Bosi, M. L. M., \& Mercado, F. J. (2004). Introdução - notas para um debate. In M. L. Bosi \& F. J. Mercado (Org.), Pesquisa qualitativa de serviços de saúde (pp. 23-71). Petrópolis, RJ: Vozes.

Chiattone, H. B. de C. (2002). A significação da psicologia no contexto hospitalar. In V. A. Angerami-Camon (Org.), Psicologia da saúde: um novo significado para a prática clínica (pp. 73-165). São Paulo: Pioneira Thomson.

Coelho Junior, N. (1996). A identidade (em crise) do psicólogo. Cadernos de Subjetividade, 4(1을 으 sem.).

Conselho Federal de Psicologia. (2005) Código de ética profissional do psicólogo. Brasília, DF.

Conselho Nacional de Saúde. (1997, 06 de março). Resolução n. 218/97. Recuperado em 12 de abril de 2004, de http:// conselho.saude.gov.br/docs/Resolucoes/Reso218.doc

Dimenstein, M. (2001). O psicólogo e o compromisso social no contexto da saúde coletiva. Psicologia em Estudo, 6(2), 57-63.

Freidson, E. (1996). Para uma análise comparada das profissões: A institucionalização do discurso e do conhecimento formais. Revista Brasileira de Ciências Sociais, 11, 141-154.

Freire, J. C. (2003). Sofrer por outrem e não sofrer de si: uma escuta do sofrimento psíquico por via da ética da alteridade radical. In Anais, VI Conferência Internacional sobre Filosofia, Psiquiatria e Psicologia - Ética, Linguagem e Sofrimento. Brasília, DF: UnB/ABRAFIPP.

Gadamer, H-G. (1997). A extensão da questão da verdade à compreensão nas ciências do espírito. Verdade e método (pp. 273-556). Petrópolis, RJ: Vozes.

Hepworth, J. (2004). Public health psychology: A conceptual and pratical framework. Journal of Health Psychology, 9(1), 41-54.
Lévinas, E. (1982). Ética e infinito. Lisboa: Edições 70.

Lévinas, E. (1988). Totalidade e infinito. Lisboa: Edições 70.

Lo Bianco, A. C., Bastos, A. V. B., Nunes, M. L. T., \& Silva, R. C. (2001). Concepções e atividades emergentes na psicologia clínica: implicações para a formação. In Conselho Federal de Psicologia (Org.), Psicólogo brasileiro: práticas emergentes e desafios para a formação (3a ed., pp. 17-100). São Paulo: Casa do Psicólogo.

Mendes, E. V. (1999). Uma agenda para a saúde (2a ed.). São Paulo: Hucitec.

Merhy, E. E. (2002). A cartografia do trabalho vivo. São Paulo: Hucitec.

Merhy, E. E., \& Franco, T. B. (2003). Por uma composição técnica do trabalho em saúde centrada no campo relacional e nas tecnologias leves. Apostando mudanças para os modelos tecnoassistenciais. Saúde em Debate, 27(65), 316-323.

Minayo, M. C. S. (2000). O desafio do conhecimento: pesquisa qualitativa em saúde (7a ed.). São Paulo: Hucitec; Rio de Janeiro: Abrasco.

Murphy, S., \& Bennett, P. (2004). Health psychology and public health: Theoretical possibilities. Journal of Health Psychology, 9(1), 13-27.

Paim, J. P., \& Almeida Filho, N. (1998). Saúde coletiva: uma "nova saúde pública" ou campo aberto a novos paradigmas? Revista de Saúde Pública, 32(4), 299-316.

Pinheiro, R., \& Guizardi, F. L. (2005). Cuidado e integralidade: Por uma genealogia de saberes e práticas no cotidiano. In R. Pinheiro \& R. A. Mattos (Orgs.), Cuidado: as fronteiras da integralidade (2a ed., pp. 21-36). Rio de Janeiro: Cepesc/ UERJ/Abrasco.

Ronzani, T. M., \& Rodrigues, M. C. (2006). O psicólogo na atenção primária à saúde: Contribuições, desafios e redirecionamentos. Psicologia: Ciência e Profissão, 26(1), 132-143.

Spink, M. J. (2003). Psicologia social e saúde: práticas, saberes e sentidos. Petrópolis, RJ: Vozes.

Stam, H. J. (2000). Theorizing health and illness: Functionalism, subjectivity and reflexivity. Journal of Health Psychology, 5(3), 273-283.

Trindade, I., \& Teixeira, J. A. C. (2000). Psicologia nos cuidados de saúde primários. Lisboa: Climepsi.

Waldow, V. R. (2004). O cuidado na saúde: as relações entre o eu, o outro e o cosmos. Petrópolis, RJ: Vozes. 